\title{
Aerosol Optical Properties over Gurushikhar, Mt. Abu: A High Altitude Mountain Site in India
}

\author{
Thazhathakal A. Rajesh ${ }^{1,2 *}$, Srikanthan Ramachandran ${ }^{1}$ \\ ${ }^{1}$ Space and Atmospheric Sciences Division, Physical Research Laboratory, Navrangpura, Ahmedabad 380009, India \\ ${ }^{2}$ Department of Physics, Sardar Patel University, Vallabh Vidyanagar, Anand 388120, India
}

\begin{abstract}
Continuous and simultaneous measurements of aerosol optical properties (the scattering and absorption coefficients) were conducted, for the first time, at a mountain site, Gurushikhar, Mt. Abu, in the Aravalli Range in western India from January 2015 to December 2016. The aerosol scattering and absorption coefficients were higher in the afternoon than during the forenoon and night because of atmospheric boundary layer dynamics that, when accompanied by strong thermal convection, promote an upward movement of pollutants to the observational site from the surrounding foothills. The aerosol scattering and absorption coefficients exhibited a strong seasonal variability. The average scattering coefficients during the winter, premonsoon, monsoon and postmonsoon seasons were 78.5 $\pm 22.9,61.8 \pm 12.2,49.9 \pm 25.1$ and $121.8 \pm$ $47.4 \mathrm{Mm}^{-1}$, respectively, and the corresponding absorption coefficients were $14.9 \pm 3.1,9.1 \pm 2.9,5.1 \pm 3.2$ and $20.2 \pm$ 10.2 $\mathrm{Mm}^{-1}$. The single scattering albedo also exhibited a significant seasonal variation, with the maximum occurring during the monsoon season (0.91) and the minimum during winter (0.83). The mean annual $\beta_{\text {sca }}, \beta_{\text {abs }}$ and SSA at $550 \mathrm{~nm}$ were $74 \pm 34 \mathrm{Mm}^{-1}, 12 \pm 7 \mathrm{Mm}^{-1}$ and $0.87 \pm 0.04$. These results indicate that Gurushikhar, a remote high altitude site, is influenced by local and long-range transported aerosols through convection and advection processes. However, the aerosol properties at this pristine location are governed by transported emissions rather than local anthropogenic sources and also display low inter-annual variability. Thus, Gurushikhar can be considered a background site for the nearby source regions in western India.
\end{abstract}

Keywords: Aerosol scattering coefficient; Aerosol absorption coefficient; Single scattering albedo; Mountain site; Interannual variability.

\section{INTRODUCTION}

Atmospheric aerosols influence the earth's radiative budget directly by scattering and absorbing the incoming solar and outgoing terrestrial radiation, and indirectly by influencing the optical properties of clouds and their lifetimes. There has been a substantial interest in studying aerosol properties and their influence on climate over different environments (e.g., ocean (Ramanathan et al., 2001); continental (Jayaraman et al., 2006); urban (Ramachandran and Kedia, 2010)). However, aerosols are still a major source of uncertainty in the prediction of climate change due to the large heterogeneity in aerosol properties, and inadequate information on the variabilities of aerosol characteristics on regional and temporal scales (IPCC, 2007). The uncertainty in the estimation of climate forcing by aerosols can be

\footnotetext{
* Corresponding author.

Tel.: +91-79-2631-4665; Fax: +91-79-26314659

E-mail address: rajeshta@prl.res.in
}

reduced by studying the seasonal and inter-annual variations in aerosol characteristics over different environments. However, most of the studies on aerosol characteristics are restricted to either urban/semi-urban regions or oceans adjacent to densely populated coastal regions (Kedia and Ramachandran, 2011, and references therein). An analysis of aerosol characteristics measured over a remote high altitude region (mountain) which is far away from the potential sources will be useful to represent regional background. High altitude locations are pristine, and aerosol characteristics over these locations are influenced mainly by the long-range transport (advection and convection processes). Hence, aerosol characteristics over high altitude remote locations can serve as a representative background site for aerosols from nearby source regions.

For the first time, in this work, results from a 2-year analysis of aerosol scattering and absorption coefficients, and single scattering albedo from the high altitude remote site in western India, measured using an integrating nephelometer and a dual spot aethalometer are presented. The results obtained from the study will be important to examine the influence of aerosols over a high altitude 
remote region in regional scale climate forcing and their global impacts.

\section{SITE DESCRIPTION AND METEOROLOGY}

The optical properties of aerosols were measured at Optical Aeronomy Laboratory, InfraRed Observatory, Physical Research Laboratory, Gurushikhar $\left(24.65^{\circ} \mathrm{N}, 72.78^{\circ} \mathrm{E}\right.$, and $1680 \mathrm{~m}$ above mean sea level (AMSL)) (Fig. 1). It is the highest point of the Aravalli Range in the Arbuda Mountains of Rajasthan. The observational site is seen to be influenced by the transport of mineral dust from the Thar Desert (northwestern part of the Indian subcontinent), sea salt from the Arabian Sea (southwestern part of the Indian subcontinent) and anthropogenic aerosols (mainly black carbon) from the Indo-Gangetic Plain (northnortheastern part of the Indian subcontinent) (Fig. 2). The city of Mount Abu (1180 m AMSL) lies downhill from

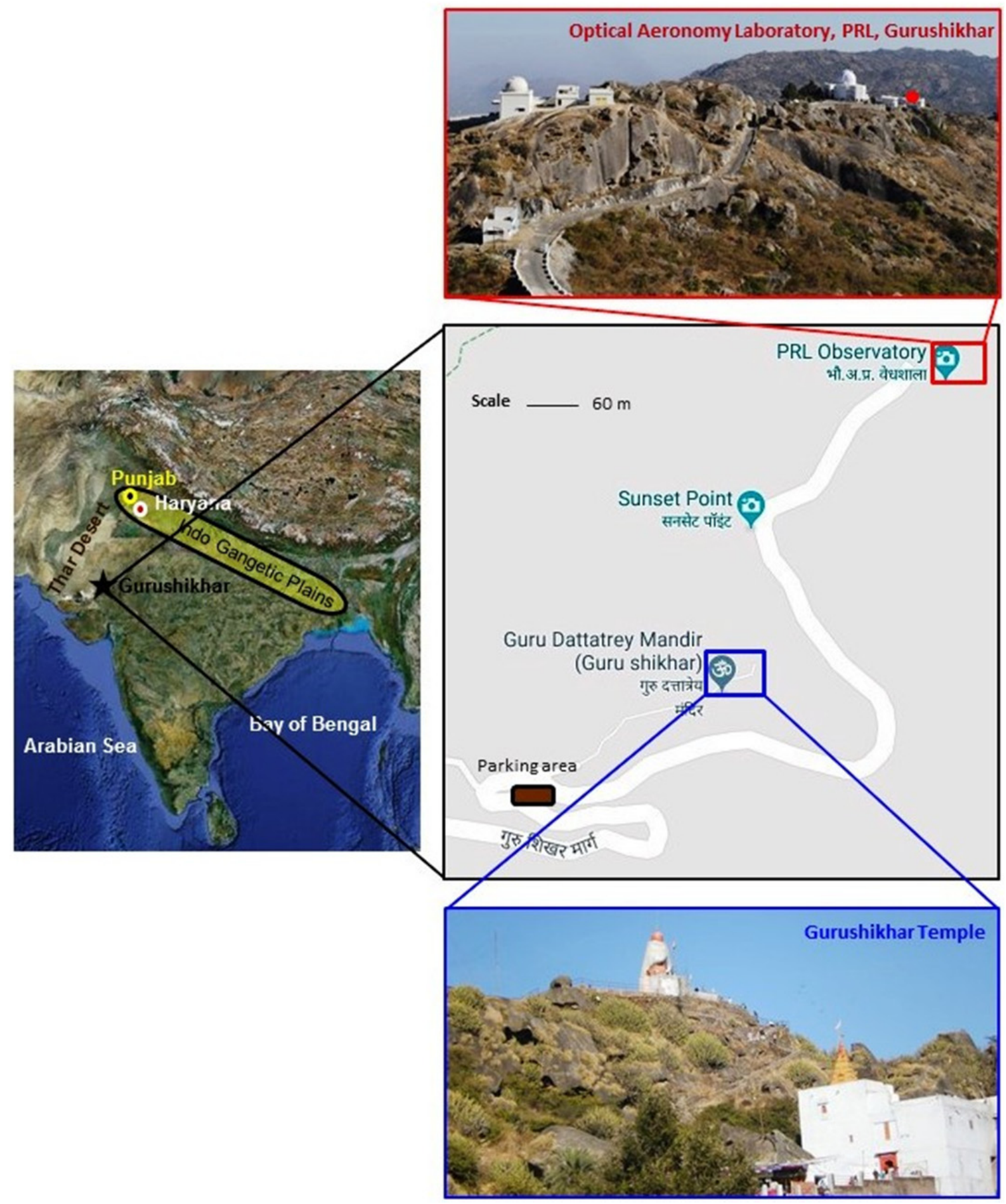

Fig. 1. The high altitude observational site in western India, Gurushikhar (1680 m), Mt. Abu; Indo-Gangetic Plain; Punjab and Haryana in India (Google Earth image). Google Maps image shows the spatial layout of Gurushikhar temple, measurement site (Optical Aeronomy Laboratory, Physical Research Laboratory (PRL), and the road pathway. 
(a) December

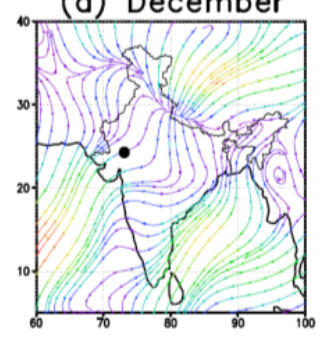

(d) March

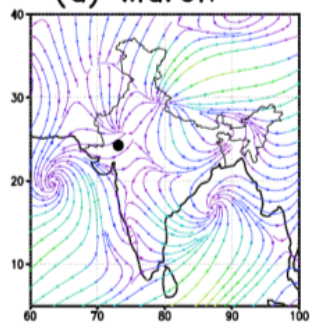

(g) June

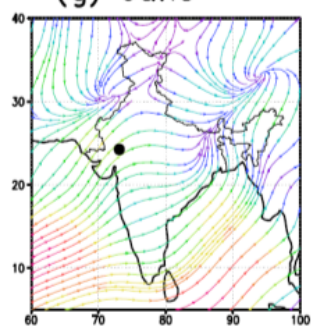

Winter

(b) January

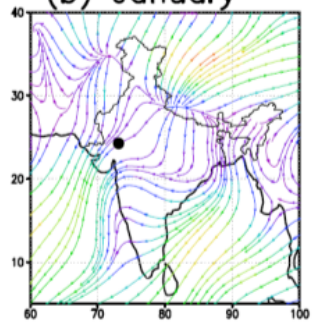

Premonsoon

(e) April

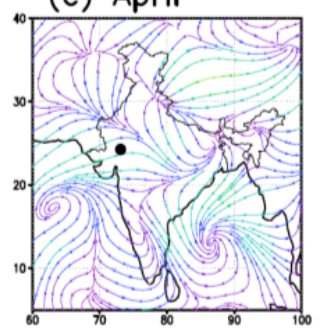

Monsoon

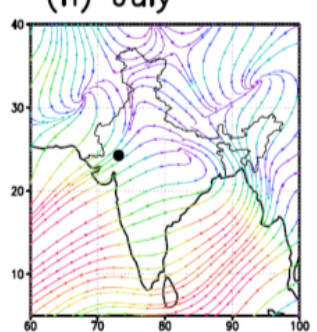

(i) August

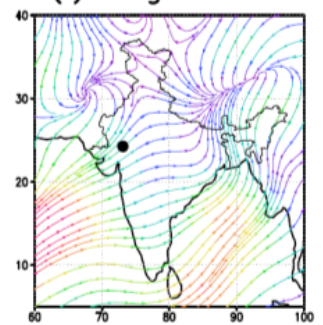

(c) February

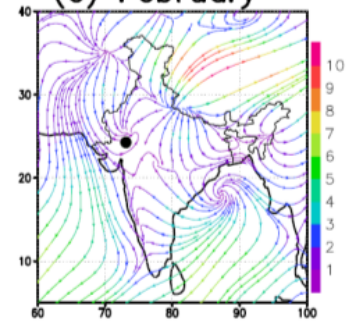

(f) May

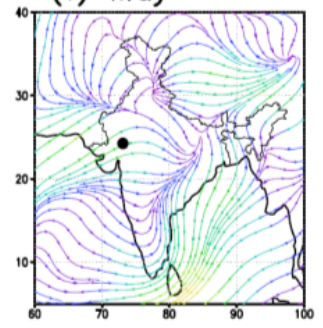

(j) September

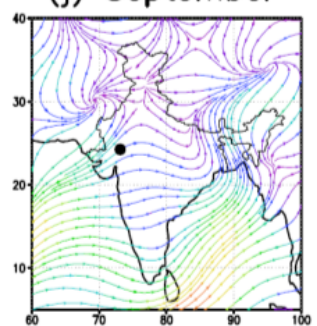

k) October
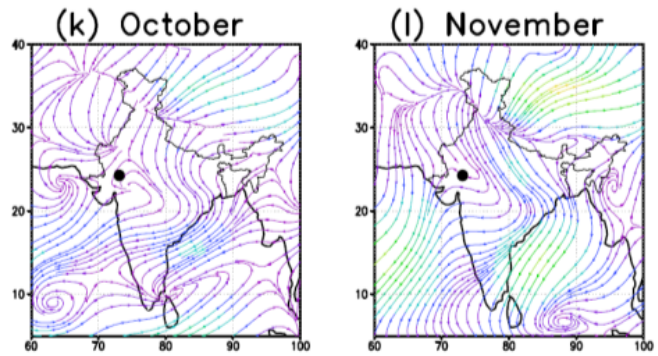

Fig. 2. Synoptic average wind stream $\left(\mathrm{m} \mathrm{s}^{-1}\right)$ over India during winter: (a) December, (b) January, and (c) February; premonsoon: (d) March, (e) April, and (f) May; monsoon: (g) June, (h) July, (i) August, and (j) September; postmonsoon: (k) October and (1) November for 2015-2016. Filled black circles represent the high altitude mountain site, Gurushikhar.

Gurushikhar at a distance of $15 \mathrm{~km}$ on a high rocky plateau and surrounded by forests. The city of Mount Abu is a popular hill station and a tourist destination in the Aravalli Range. To the northwest of Gurushikhar lies Abu Road (280 m AMSL) at a distance of $40 \mathrm{~km}$ in the hills of the Aravalli Range which has anthropogenic activity. A famous temple (Guru Dattatrey Mandir), which is situated at an aerial distance of about $450 \mathrm{~m}$ from the measurement site, attracts a large number of people during the year. The measurement site is approximately $650 \mathrm{~m}$ away from the visitor parking area.

The mean synoptic surface winds over the study region exhibit significant variability in speed and direction (Fig. 2). During premonsoon, the winds originate and travel from the western Indian region, while during monsoon the winds are stronger and moist, and are from the marine (Arabian Sea), and western regions surrounding India. During postmonsoon, the wind pattern starts shifting in direction from southwest to northeast, whereas during winter the surface winds are calm and north-northeasterly. In order to further examine the source regions and the transport pathways of pollutants over Gurushikhar, 7 day (average residence time of aerosols in the lower atmosphere) back trajectory analysis was performed using the Hybrid Single Particle Lagrangian Integrated Trajectory (HYSPLIT, version 4.9) model (http://ready.arl.noaa.gov/HYSPLIT.php). Air back trajectories at a receptor site provide vital information about the potential source contribution regions 
of atmospheric pollutants. The daily trajectory in each month was assigned to clusters according to their magnitude and direction using the inherited clustering algorithm (k-means) in the HYSPLIT model. The number of clusters is determined from the total spatial variance plot using the HYSPLIT model and each trajectory cluster signifies the grouping of similar trajectories. Trajectory clustering minimizes the variability among the trajectories within a cluster and maximizes the variability between the clusters (Reddy et al., 2012). The cluster mean trajectories and their contributions (percentage) are computed for each month at $1550 \mathrm{~m}$ above ground level (AGL) $(\sim 823 \mathrm{hPa})$ at the observational site (Fig. 3 ), as this height is very close to the surface pressure $(\sim 830 \mathrm{hPa})$.

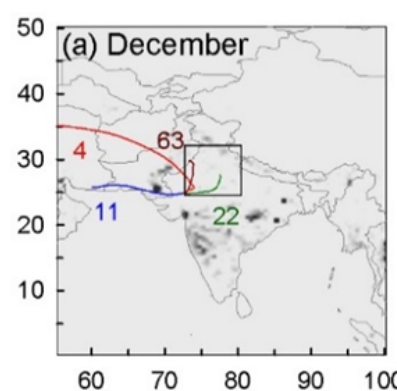

\section{Winter}

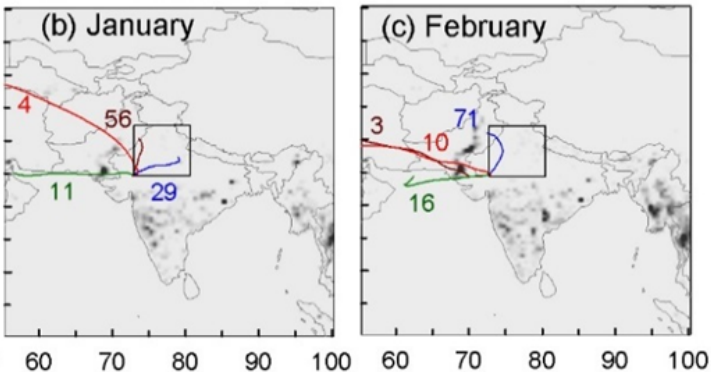

Premonsoon
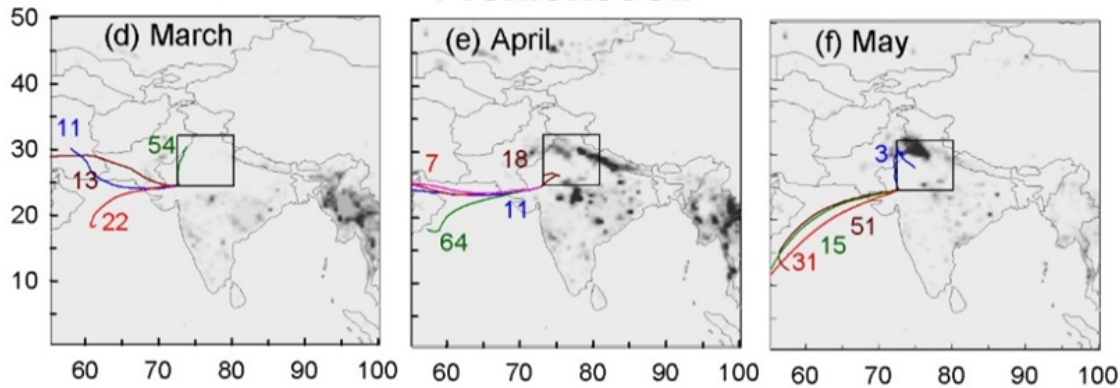

Monsoon
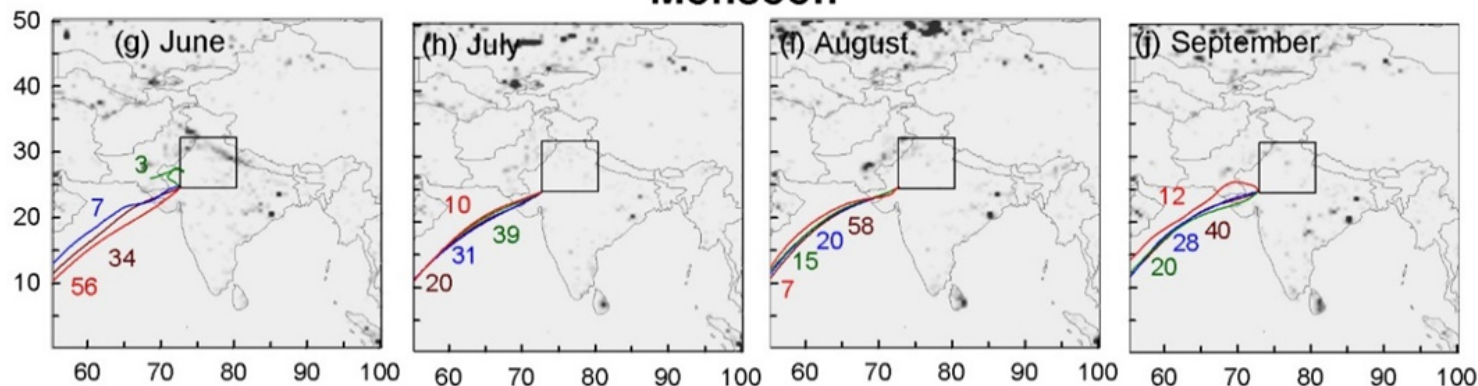

\section{Postmonsoon}
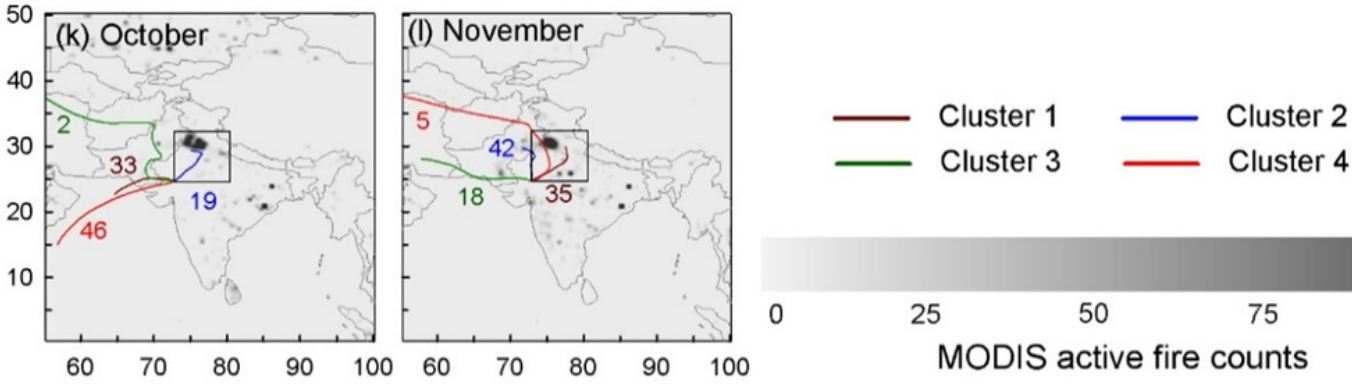

Fig. 3. Monthly mean cluster plot over Gurushikhar during winter: (a) December, (b) January, and (c) February; premonsoon: (d) March, (e) April, and (f) May; monsoon: (g) June, (h) July, (i) August, and (j) September; postmonsoon: (k) October and (1) November for 2015-2016. The mean trajectory of Clusters 1, 2, 3, and 4 are drawn in brown, blue, green, and red respectively. Cluster number values represent the percentage of backward air trajectories in each cluster. MODIS active monthly fire counts are also plotted over India during 2015 and 2016. The square box represents the grid containing the significant fire counts. 
The meteorological parameters (air temperature, relative humidity, and wind speed) were measured using Vaisala Weather Transmitter WXT520 at Gurushikhar, Mt. Abu, during 2015-2016. Depending on the prevailing meteorology the entire year has been classified into four major seasons, namely, winter (December-January-February), premonsoon (March-April-May), monsoon (June-July-AugustSeptember) and postmonsoon (October-November). The monthly mean air temperature is highest during May $\left(25^{\circ} \mathrm{C}\right)$ and lowest during January $\left(12^{\circ} \mathrm{C}\right)$ (Table 1$)$ over Gurushikhar. Relative humidity $(\mathrm{RH})$ is high in August $(86 \%)$ and is low in December $(25 \%)$ (Table 1$)$. The surface wind speeds are maximum in July $\left(4.8 \mathrm{~m} \mathrm{~s}^{-1}\right)$ and minimum in December $\left(1.5 \mathrm{~m} \mathrm{~s}^{-1}\right)$ (Table 1). The rainfall over Gurushikhar is distributed over the premonsoon and monsoon seasons (Table 1) with maximum rainfall occurring in July (567 mm).

\section{INSTRUMENTS AND MEASUREMENTS}

\section{Integrating Nephelometer}

An integrating nephelometer (Model 3563; TSI Inc., USA) is used to measure aerosol scattering coefficients $\left(\beta_{\text {sca }}\right)$ at 450, 550 and $700 \mathrm{~nm}$. The instrument draws air sample through an inlet port into measurement volume, where the volume is illuminated by a flash lamp and the scattered light intensity is measured by three photomultiplier tubes kept perpendicular to air flow. The total scattered light is integrated over an angular range of $7-170^{\circ}$ from the forward direction. The instrument is periodically programmed for an auto-zero calibration using a high efficiency filter to obtain a measure of clean air signal pertaining to the operating environment. The span calibration is done by passing ultra-high pure $\mathrm{CO}_{2}$ gas and the instrument is regularly calibrated according to the procedure described in the operations manual. Measurements of $\beta_{\text {sca }}$ were conducted in a continuous mode with data averaging time of 5 minutes at a flow rate of $20 \mathrm{~L} \mathrm{~min}^{-1}$.

Nephelometer measured raw aerosol scattering coefficient $\left(\beta_{\text {sca(raw) }}\right)$ needs to be corrected for missing forward scattering, and for temperature and pressure variations. The nephelometer performs a truncation of scattered radiation at $<7^{\circ}$ scattering angle and this missing forward scattering is corrected following Anderson and Ogren (1998) as:

$\mathrm{B}_{\mathrm{sca}}=\beta_{\mathrm{sca}(\text { raw })} C_{t s}(\lambda)$

$C_{t s}(\lambda)=\mathrm{a}+\mathrm{b} \AA$

where $\beta_{\text {sca }(\text { raw })}$ is the raw scattering coefficient, $C_{t s}(\lambda)$ is the correction factor, and $\AA$ is Ångström scattering exponent, and represented as:

$$
\AA=\frac{-\ln \left(\beta_{s c a}\left(\lambda_{1}\right) / \beta_{\text {sca }}\left(\lambda_{2}\right)\right)}{\ln \left(\lambda_{1 /} \lambda_{2}\right)}
$$

The nephelometer is calibrated at standard temperature and pressure (STP), and variations in temperature and pressure from STP are corrected following:

$$
\beta_{\text {sca }}=\beta_{\text {sca }} \frac{T}{273.2} \frac{1013.2}{P}
$$

where $\mathrm{T}$ is absolute temperature $(\mathrm{K})$ and $P$ is pressure $(\mathrm{hPa})$. The overall uncertainty in $\beta_{\text {sca }}$, taking into account the above sources of uncertainty is estimated to be about $15 \%$.

\section{Dual Spot Aethalometer}

Aethalometer is an optical attenuation based instrument used for the measurement of aerosol absorption coefficient in ambient air. It primarily gives black carbon (BC) mass concentration at 7 wavelengths $(370,470,520,590,660$, 880 and $950 \mathrm{~nm}$ ) which is further converted to aerosol absorption coefficient ( $\beta_{\text {abs }}$ ) using mass specific attenuation cross section (Rajesh and Ramachandran, 2018). The single spot aethalometers were found to exhibit non-linearity due to aerosol loading effect (Weingartner et al., 2003; Arnott et al., 2005; Virkkula et al., 2007), and hence, in order to compensate for the non-linearity in real-time $\mathrm{BC}$ mass concentration measurements, aethalometer based on dual spot attenuation measurement technique was developed (Drinovec et al., 2015). In the dual spot aethalometer

Table 1. Mean monthly temperature $\left(\mathrm{T},{ }^{\circ} \mathrm{C}\right)$, relative humidity $(\mathrm{RH}, \%)$, and monthly accumulated rainfall $(\mathrm{RF}$, mm) over Gurushikhar, Mt. Abu, during January 2015-December 2016.

\begin{tabular}{lllll}
\hline Months & $\mathrm{T}\left({ }^{\circ} \mathrm{C}\right)$ & $\mathrm{RH}(\%)$ & WS $\left(\mathrm{m} \mathrm{s}^{-1}\right)$ & $\mathrm{RF}(\mathrm{mm})$ \\
\hline Jan & $12.4 \pm 2.9$ & $40.0 \pm 21.0$ & $1.7 \pm 0.9$ & 0.0 \\
Feb & $14.5 \pm 3.2$ & $33.6 \pm 17.0$ & $1.8 \pm 0.8$ & 0.0 \\
Mar & $17.8 \pm 3.6$ & $29.8 \pm 14.3$ & $1.7 \pm 0.7$ & 5.8 \\
Apr & $21.7 \pm 2.9$ & $33.5 \pm 16.0$ & $3.1 \pm 0.8$ & 4.3 \\
May & $25.0 \pm 2.8$ & $36.6 \pm 17.1$ & $2.9 \pm 0.8$ & 221.3 \\
Jun & $24.1 \pm 2.8$ & $39.5 \pm 18.4$ & $3.6 \pm 0.9$ & 567.2 \\
Jul & $21.0 \pm 2.0$ & $70.0 \pm 15.0$ & $4.8 \pm 1.1$ & 322.9 \\
Aug & $18.5 \pm 1.9$ & $86.0 \pm 12.0$ & $3.2 \pm 0.8$ & 8.6 \\
Sep & $17.0 \pm 1.8$ & $80.0 \pm 11.0$ & $3.3 \pm 0.9$ & 0.0 \\
Oct & $16.5 \pm 2.1$ & $51.1 \pm 13.9$ & $3.2 \pm 0.6$ & 0.0 \\
Nov & $16.8 \pm 2.3$ & $36.2 \pm 16.8$ & $2.6 \pm 0.5$ & 0.0 \\
Dec & $15.2 \pm 3.5$ & $25.0 \pm 16.9$ & $1.5 \pm 0.6$ & \\
\hline
\end{tabular}


(AE33; Magee Scientific), simultaneous measurements are obtained from two independent sample spots with respect to a blank reference filter spot and each sample spot has different flow rates (Drinovec et al., 2015). The outputs from both the sample spots are then combined to eliminate non-linearity and further used to estimate the compensated aerosol light attenuation to provide real-time BC mass concentration (Rajesh and Ramachandran, 2018). The light attenuation through the sample spots can be parameterized by a non-linear empirical relationship given by Gundel et al. (1984) as:

$$
\begin{aligned}
& A T N 1=\frac{1}{k}\left(1-e^{-k B_{1} \sigma}\right) \\
& A T N 2=\frac{1}{k}\left(1-e^{-k B_{2} \sigma}\right)
\end{aligned}
$$

where $k$ is filter loading effect compensation parameter, $B_{1}$ and $B_{2}$ are the aerosol loadings on the two independent sample spots. $k$ is estimated in real-time using the above equations as:

$$
\frac{F_{2}}{F_{1}}=\frac{\ln (1-k \text { ATN } 2)}{\ln (1-k A T N 1)}
$$

where $F_{1}$ and $F_{2}$ are the volumetric flow rates through the individual sample spots. The filter loading effect compensated black carbon mass concentration is estimated using the attenuation measured on the spot with higher flow as:

$$
B C=\frac{A\{d(A T N 1) / 100\}}{F_{1}(1-\phi) \sigma C(1-k A T N 1) d t}
$$

where $\phi$ is the lateral airflow in the filter matrix and is estimated with measured input and output flow rates $\left(F_{\text {input }}=\right.$ $\left.F_{\text {output }}(1-\phi)\right)$, A is the sample spot area, $C$ is enhancement parameter that arises due to multiple scattering effects; for Teflon coated fiber filter $\mathrm{C}$ is 1.57. $\sigma$ is the mass specific attenuation cross section which is instrument dependent and varies as a function of wavelength (Rajesh and Ramachandran, 2018). Aerosol absorption coefficient ( $\beta_{\text {abs, }}$, $\mathrm{Mm}^{-1}$ ) is further computed as:

$$
\beta_{\mathrm{abs}}=B C \sigma \text {. }
$$

The dual spot aethalometer (AE33) was operated at a flow rate of $3 \mathrm{~L} \mathrm{~min}{ }^{-1}$ with the time base of $1 \mathrm{~min}$. The total uncertainty in $\beta_{\text {abs }}$ due to variation in filter scattering because of aerosol loading, sample flow rates, filter spot area and detector response is estimated to be about $10 \%$ (Rajesh and Ramachandran, 2018). The absorption coefficient at $550 \mathrm{~nm}$ is derived using the absorption coefficients measured at 7 wavelengths $(370,470,520,590,660,880$ and $950 \mathrm{~nm}$ ) following the wavelength dependence of $\beta_{\text {abs }}$ (Rajesh and Ramachandran, 2018).
Both the instruments were sampling the ambient air through a common manifold with sampling inlet mounted $10 \mathrm{~m}$ above ground level. A total of 524 and 536 days of $\beta_{\text {sca }}$ and $\beta_{\text {abs }}$ data were available during the 2-year period which are analyzed. The data gaps occurred due to raw power failure, UPS failure, and maintenance of instruments (Table 2).

\section{RESULTS AND DISCUSSION}

\section{Diurnal Characteristics}

The scattering $\left(\beta_{\text {sca }}\right)$ and absorption $\left(\beta_{\text {abs }}\right)$ coefficients represent the attenuation of the solar radiation due to scattering and absorption by aerosols respectively. The aerosol optical properties (scattering $\left(\beta_{\text {sca }}\right)$ and absorption $\left(\beta_{\text {abs }}\right)$ coefficients at $550 \mathrm{~nm}$ ) exhibit atypical diurnal variability (Figs. 4-5) different than the diurnal variability observed over any source region (e.g., urban (Ramachandran and Kedia, 2010). Over an urban site high values of $\beta_{\text {sca }}$ and $\beta_{\mathrm{abs}}$ are typically reported during morning (07:0009:00 local time) and late evening (19:00-21:00) due to the substantial increase in the anthropogenic activities and the atmospheric boundary layer dynamics, which decreases as day advances (due to the evolution of the atmospheric boundary layer) and attains its minimum value around 15:00-16:00 (Ramachandran and Kedia, 2010). By contrast, $\beta_{\text {sca }}$ and $\beta_{\mathrm{abs}}$ over Gurushikhar show a late afternoon maxima and a midnight minimum. This odd diurnal feature in aerosol characteristics arises due to the evolution of the atmospheric boundary layer which transports the pollutants from the foothills to the observational location during the afternoon hours. During daytime, after the sunrise, the land gets heated up which results in the convective motion of the air parcels (Kovalev and Eichinger, 2004), which in turn increases the vertical mixing of air and results in the higher values of $\beta_{\text {sca }}$ and $\beta_{\text {abs }}$ at the study location. The observations reveal that vertical transport of pollutants from the valley regions by the evolving atmospheric boundary

Table 2. The number of days aerosol scattering $\left(\beta_{\text {sca }}\right)$ and absorption $\left(\beta_{\text {abs }}\right)$ coefficient measurements were made over Gurushikhar, Mt. Abu, during January 2015 and December 2016. The data gaps are due to power failure, UPS failure, and maintenance of instruments.

\begin{tabular}{llllll}
\hline \multirow{2}{*}{ Months } & \multicolumn{3}{c}{$\beta_{\text {sca }}$} & & \multicolumn{2}{c}{$\beta_{\text {abs }}$} \\
\cline { 2 - 3 } \cline { 5 - 5 } & 2015 & 2016 & & 2015 & 2016 \\
\hline Jan & 16 & 29 & & 16 & 30 \\
Feb & 28 & 29 & 28 & 28 \\
Mar & 31 & 31 & & 31 & 31 \\
Apr & 22 & 26 & 20 & 13 \\
May & 20 & 31 & & 15 & 30 \\
Jun & 15 & 19 & & 02 & 02 \\
Jul & 15 & 29 & & 15 & 29 \\
Aug & 07 & 19 & 18 & 28 \\
Sep & 00 & 00 & 27 & 26 \\
Oct & 24 & 25 & 18 & 21 \\
Nov & 20 & 28 & 28 & 30 \\
Dec & 28 & 31 & 22 & 28 \\
\hline
\end{tabular}




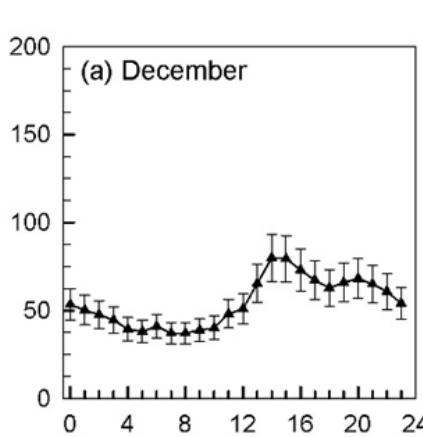

Winter

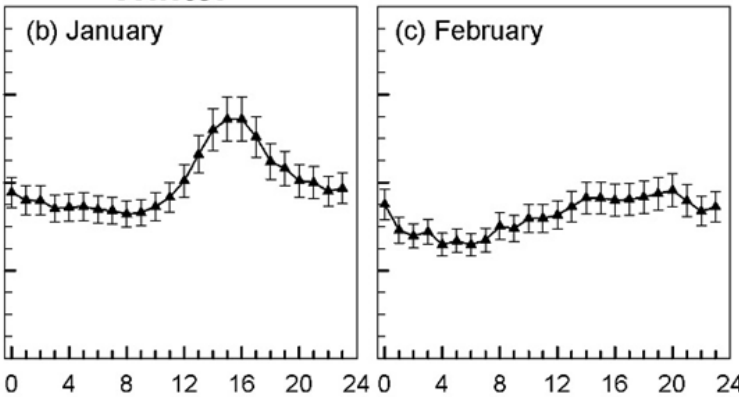

Premonsoon
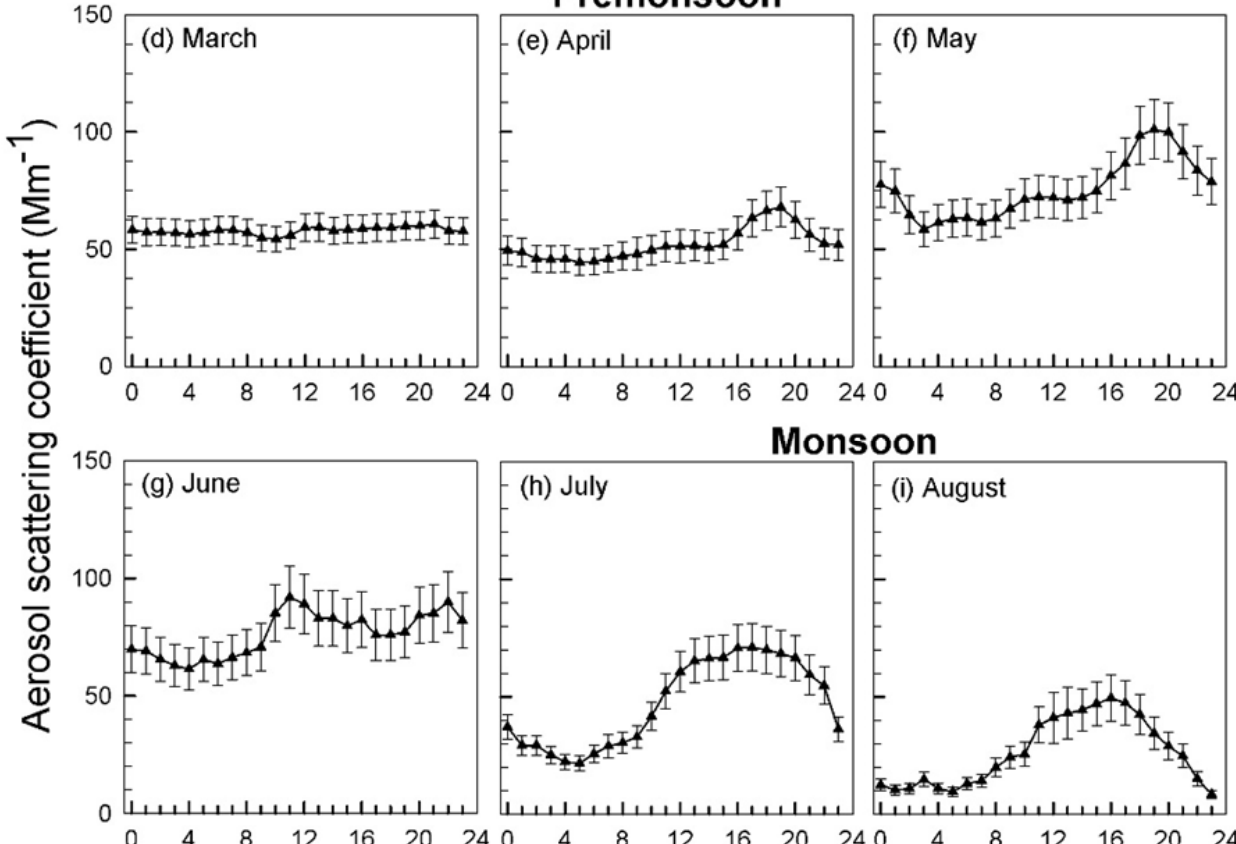

Monsoon

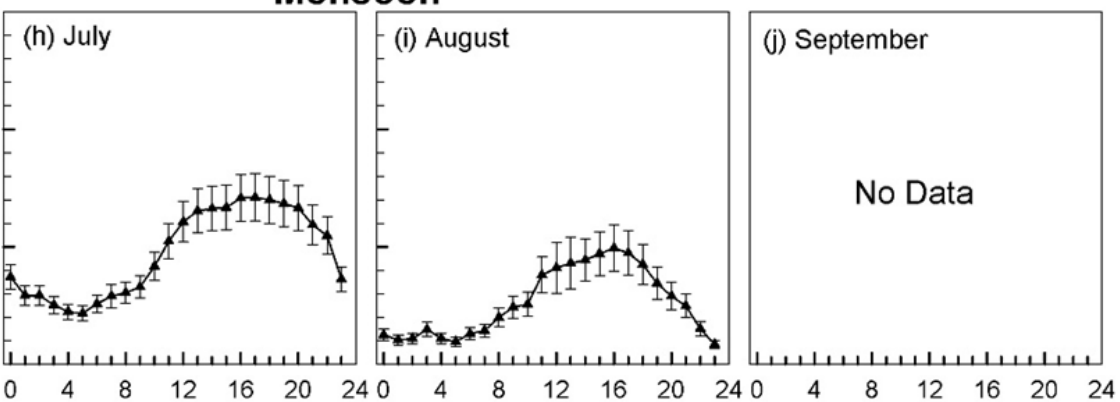

Postmonsoon

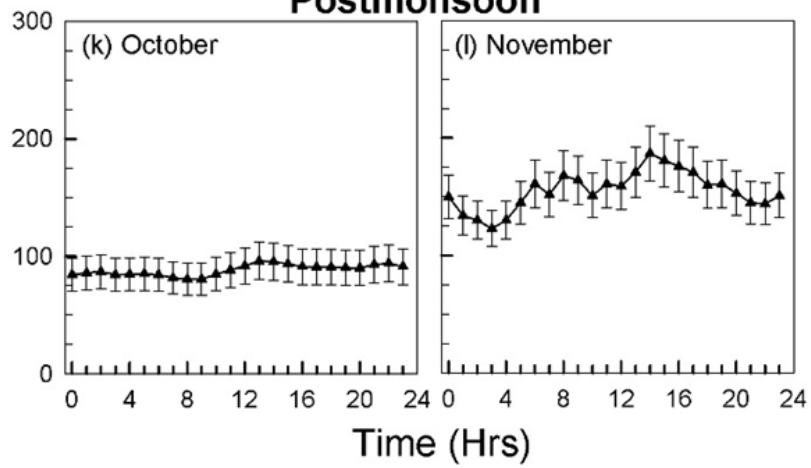

Fig. 4. Monthly diurnal variation of aerosol scattering coefficient $\left(\beta_{\mathrm{sca}}, \mathrm{Mm}^{-1}\right)$ over Gurushikhar during winter: (a) December, (b) January, and (c) February; premonsoon: (d) March, (e) April, and (f) May; monsoon: (g) June, (h) July, (i) August, and (j) September; postmonsoon: (k) October and (l) November for 2015-2016 at $550 \mathrm{~nm}$. Vertical bars represent $\pm 1 \sigma$ variation about the mean.

layer modulates the aerosol concentration at the observational peak. Hence, the observed $\beta_{\text {sca }}$ and $\beta_{\text {abs }}$ during the afternoon hours are higher than forenoon (Figs. 4-5). $\beta_{\text {sca }}$ and $\beta_{\text {abs }}$ show similar variations over the measurement location (Figs. 4-5), however, $\beta_{\text {sca }}$ is higher than $\beta_{\text {abs }}$ by a factor of 6 throughout the year. The difference between the maximum and the minimum value of the day is called the diurnal amplitude. The maximum amplitude of diurnal variation in $\beta_{\mathrm{sca}}$ and $\beta_{\mathrm{abs}}$ are $\sim 54$ and $10 \mathrm{Mm}^{-1}$ respectively during January. January is the coldest month; because of colder temperatures people burn biomass materials to keep them warm throughout the hills resulting in an increase in the anthropogenic/biomass burning emissions. The minimum amplitude of diurnal variation in $\beta_{\text {sca }}$ and $\beta_{\text {abs }}$ are $\sim 6$ and 

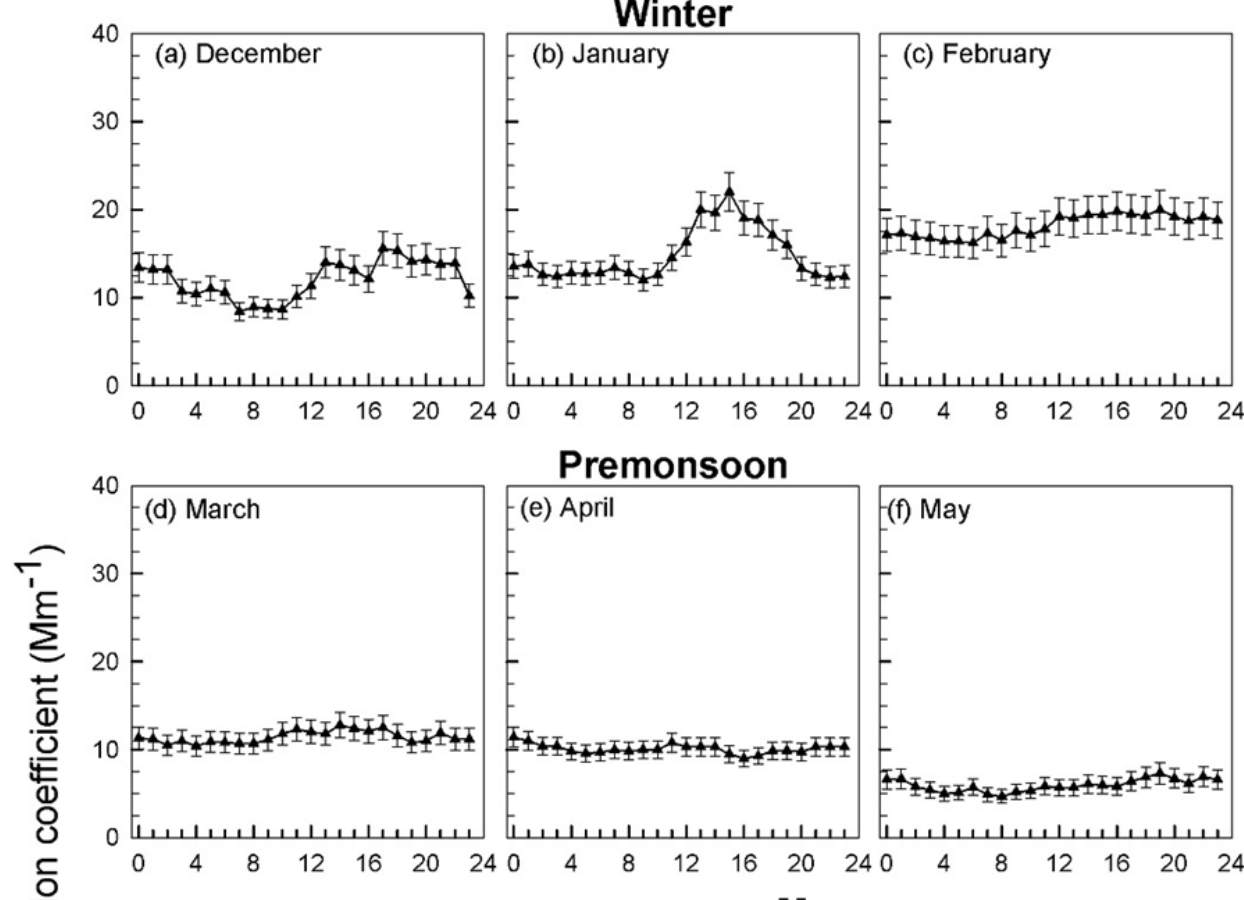

Premonsoon
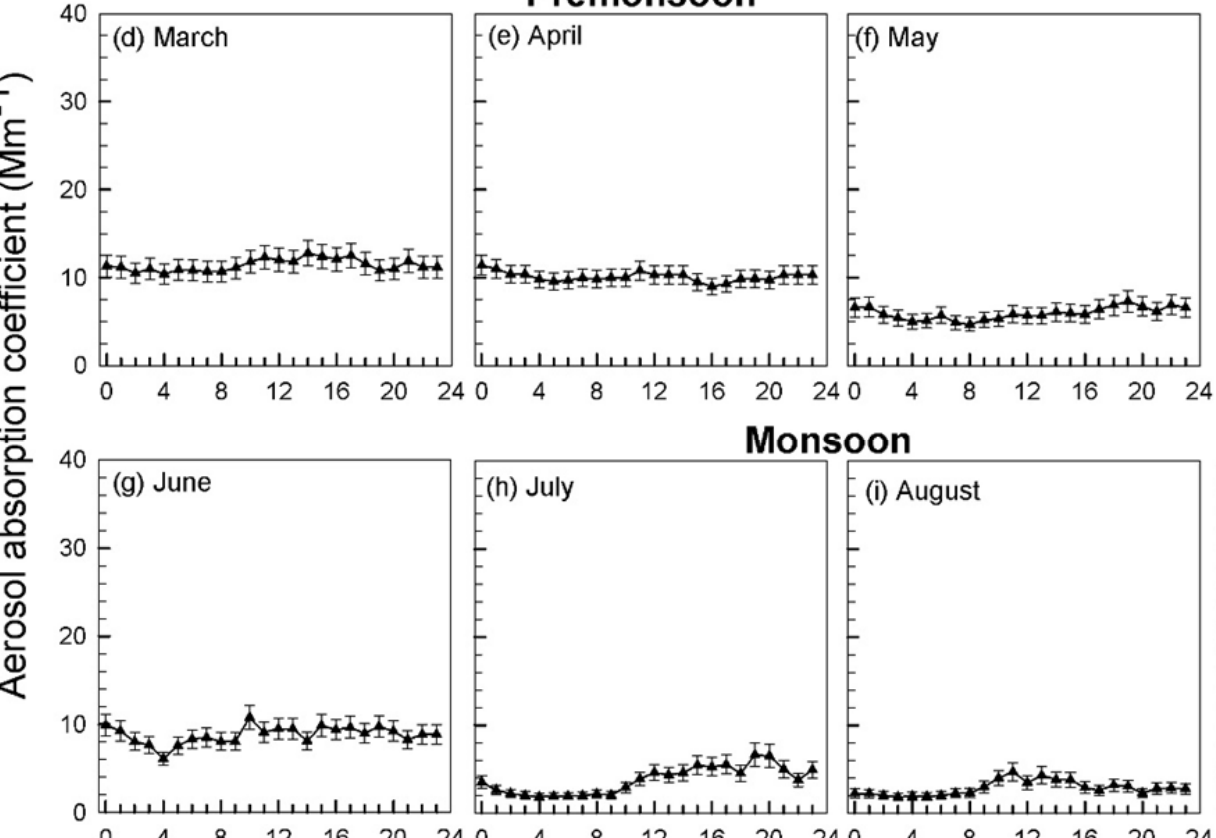

Monsoon
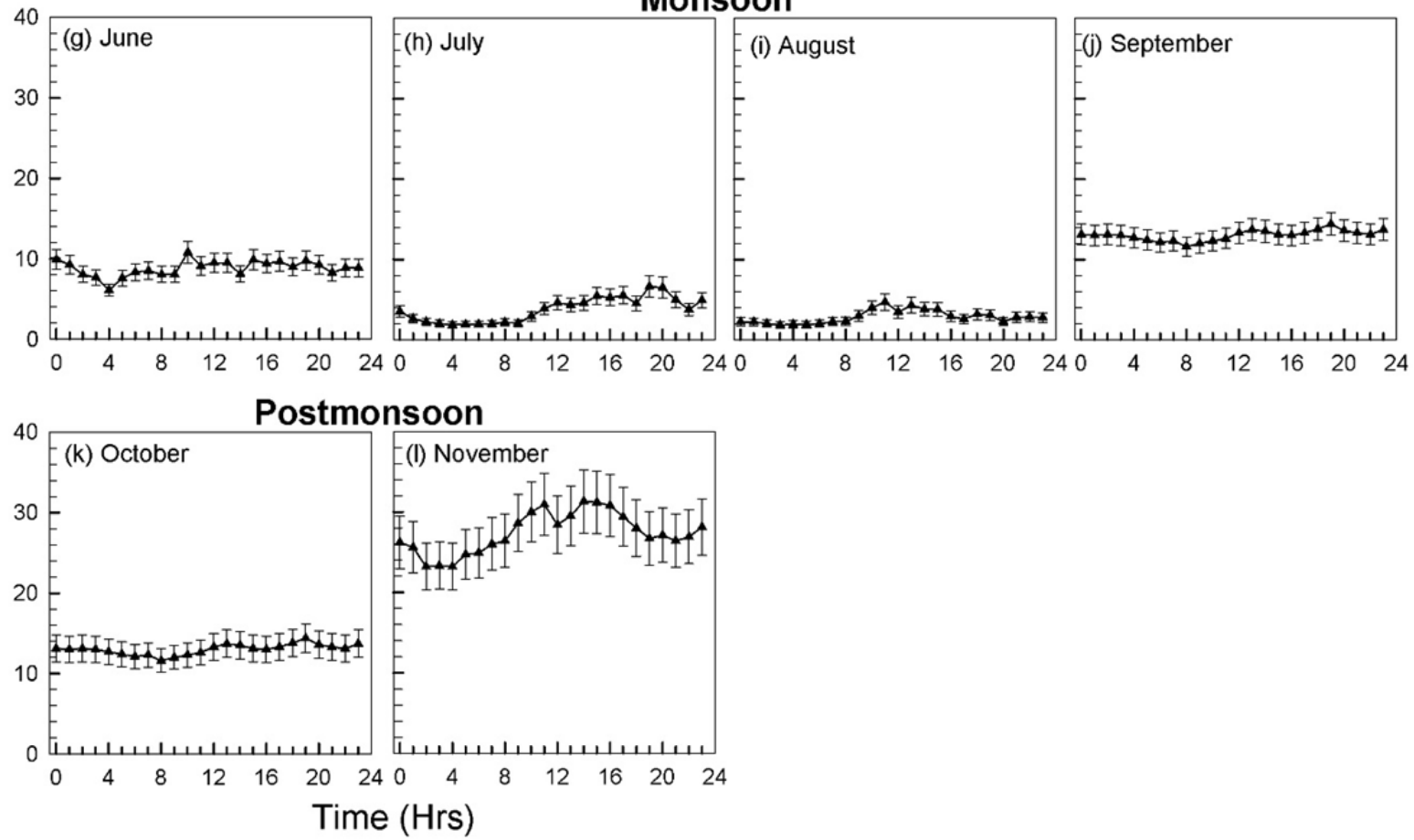

Fig. 5. Monthly diurnal variation of aerosol absorption coefficient $\left(\beta_{\mathrm{abs}}, \mathrm{Mm}^{-1}\right)$ over Gurushikhar during winter: (a) December, (b) January, and (c) February; premonsoon: (d) March, (e) April, and (f) May; monsoon: (g) June, (h) July, (i) August, and (j) September; postmonsoon: (k) October and (l) November for 2015-2016 at $550 \mathrm{~nm}$. Vertical bars represent $\pm 1 \sigma$ variation about the mean.

$2 \mathrm{Mm}^{-1}$ during March respectively (Figs. 4-5) probably due to the minimum influence of the anthropogenic emissions at the observational site. The maximum (54\%) contribution of long-range transport of the air parcels are from the non-fire affected areas (Fig. 3). These effects may give rise to minimal diurnal amplitude during March.

Single scattering albedo (SSA), defined as the ratio between the scattering coefficient $\left(\beta_{\text {sca }}\right)$ and the extinction (sum of scattering $\left(\beta_{\mathrm{sca}}\right)$ and absorption $\left(\beta_{\mathrm{abs}}\right)$ ) coefficient of aerosols, can range from 0 (purely absorbing aerosols) to 1 (purely scattering aerosols). A higher SSA indicates the dominance of scattering aerosols as compared to the absorbing aerosols in the aerosol distribution. The maximum relative standard error in the estimated value of SSA is 
$<10 \%$. SSA at $550 \mathrm{~nm}$ over Gurushikhar also exhibits a rare diurnal variability (Fig. 6) different than the variability observed commonly at other environmentally distinct locations (Ramachandran and Kedia, 2010, and references therein). Typically, over an urban location SSA shows two minima during the morning (07:00-09:00) and evening (19:00-20:00) coinciding with morning and evening $\beta_{\text {sca }}$ and $\beta_{\text {abs }}$ peaks due to the dominance of absorbing aerosols from the anthropogenic activities, and an afternoon maximum as absorbing aerosol emissions decrease. The SSA decreases sharply after 21:00 due to the consistent decrease in $\beta_{\text {sca }}$ (Fig. 4). This peculiar behavior in SSA is probably due the characteristic feature of the influence of local/regional meteorology which consistently decreases the supply of scattering type aerosols to the observation location.
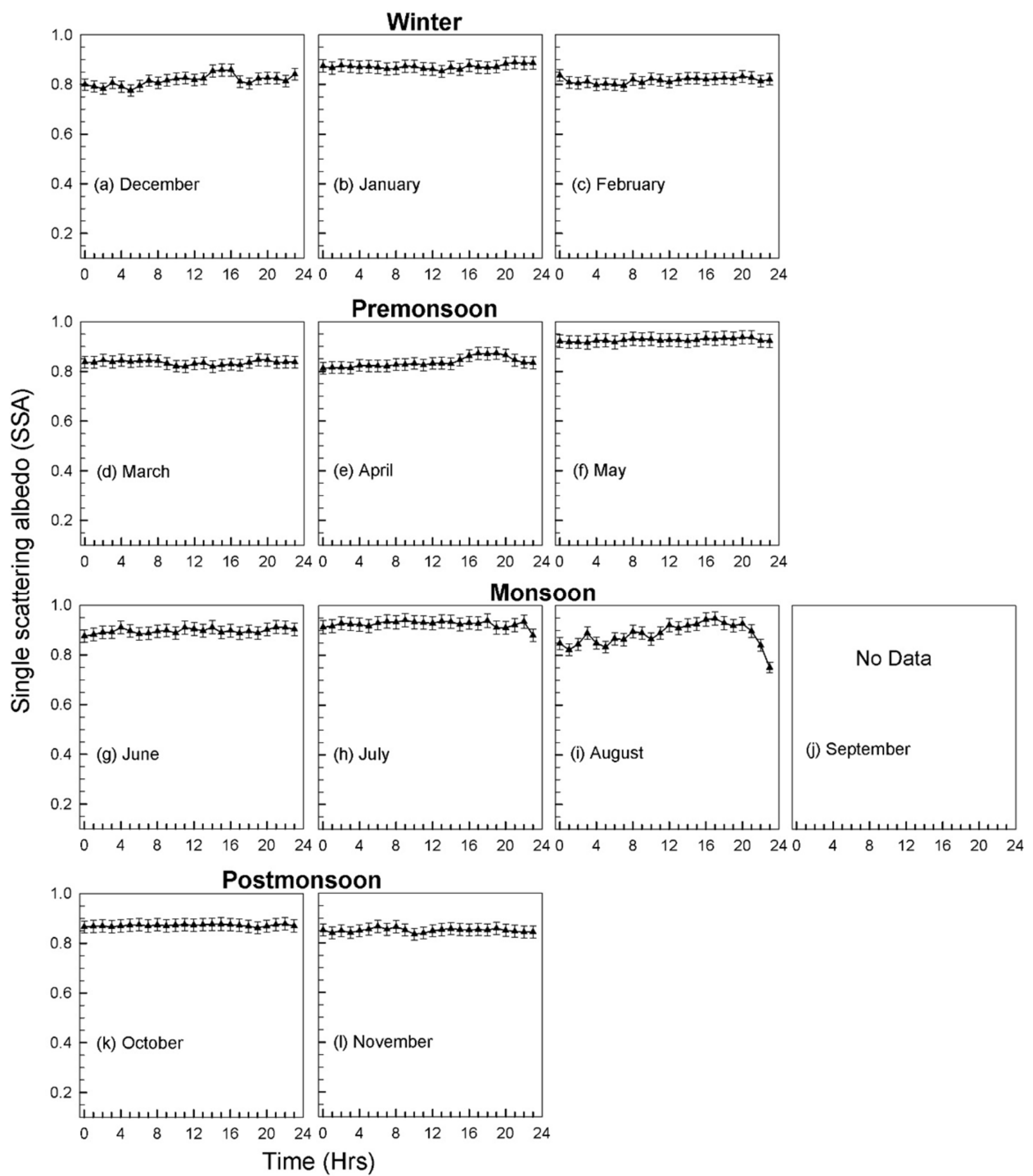

Fig. 6. Monthly diurnal variation of single scattering albedo (SSA) over Gurushikhar during winter: (a) December, (b) January, and (c) February; premonsoon: (d) March, (e) April, and (f) May; monsoon: (g) June, (h) July, (i) August, and (j) September; postmonsoon: (k) October and (1) November for 2015-2016 at $550 \mathrm{~nm}$. 


\section{Monthly and Seasonal Characteristics}

The high altitude observational site (Gurushikhar) has been found to have minimum or negligible anthropogenic emissions. The aerosol scattering $\left(\beta_{\text {sca }}\right)$ and absorption $\left(\beta_{\text {abs }}\right)$ coefficients at $550 \mathrm{~nm}$ decrease from January to April and then increase during May and June, which again decrease afterward till August and then increase from October to November before becoming low in December (Figs. 7(a)7(b)). The maximum $\beta_{\text {sca }}\left(155.3 \mathrm{Mm}^{-1}\right)$ and $\beta_{\text {abs }}\left(27.4 \mathrm{Mm}^{-1}\right)$ are observed during November as in addition to the anthropogenic emission from the nearby region, it is strongly influenced by the long-range transport (77\%) from the northern part of India (Fig. 3). The factors causing high aerosol scattering and absorption coefficients are due to transport through convective (transport from the foothills) and advective (long-range transport) processes. The minimum $\beta_{\text {sca }}\left(26.3 \mathrm{Mm}^{-1}\right)$ and $\beta_{\text {abs }}\left(2.8 \mathrm{Mm}^{-1}\right)$ are observed during August due to the removal of aerosols by precipitation (Table 1). $\beta_{\text {sca }}$ and $\beta_{\text {abs }}$ show a strong seasonal variation over Gurushikhar. $\beta_{\text {sca }}$ and $\beta_{\text {abs }}$ are highest during postmonsoon (121.8 and $20.2 \mathrm{Mm}^{-1}$ ) followed by winter (78.5 and $15.0 \mathrm{Mm}^{-1}$ ), as the location is affected significantly by convection and advection (Fig. 3). In addition, during postmonsoon and winter there is a significant increase in the amount of biomass burning, and the tourist activities (resulting in an increase in vehicular emission) in the region. $\beta_{\mathrm{sca}}$ and $\beta_{\mathrm{abs}}$ decrease during premonsoon due to the change in the wind direction and source region (arid to marine). The minimum $\beta_{\text {sca }}\left(49.9 \mathrm{Mm}^{-1}\right)$ and $\beta_{\text {abs }}\left(5.1 \mathrm{Mm}^{-1}\right)$ are observed during monsoon due to the wet removal. The cluster distribution shows that during monsoon winds are entirely from the Arabian Sea, whereas, during postmonsoon the air is from the fire affected areas (Punjab and Haryana) (Fig. 3). During winter the maximum cluster contributions are from the land mass $(75 \%, 85 \%$ and $71 \%$ in December, January and February) (Fig. 3), whereas premonsoon exhibit the changes in wind direction from March to May (Fig. 3). During May the maximum air parcels are from the Arabian Sea which resulted in higher contribution of aerosol scattering coefficient as compared to aerosol absorption coefficient (Figs. 4-5). The annual mean $\beta_{\text {sca }}$ and $\beta_{\text {abs }}$ are found to be 74 and $12 \mathrm{Mm}^{-1}$ respectively over Gurushikhar. It is interesting to note that monthly mean variability of $\beta_{\text {sca }}$ is different than that of $\beta_{\text {abs }}$, but the seasonal mean $\beta_{\text {sca }}$ and $\beta_{\text {abs }}$ go hand in hand. Annual mean $\beta_{\text {sca }}\left(78.8 \mathrm{Mm}^{-1}\right)$ found over Gurushikhar is lower than the values reported over an urban location in western India (Ganguly et al., 2006). Gurushikhar $\beta_{\text {sca }}$ is also found to be lower than various urban, suburban, rural, and mountain sites in China (Li et al., 2017).

Single scattering albedo (SSA) also exhibits significant monthly and seasonal variations (Fig. 7(c)). The maximum

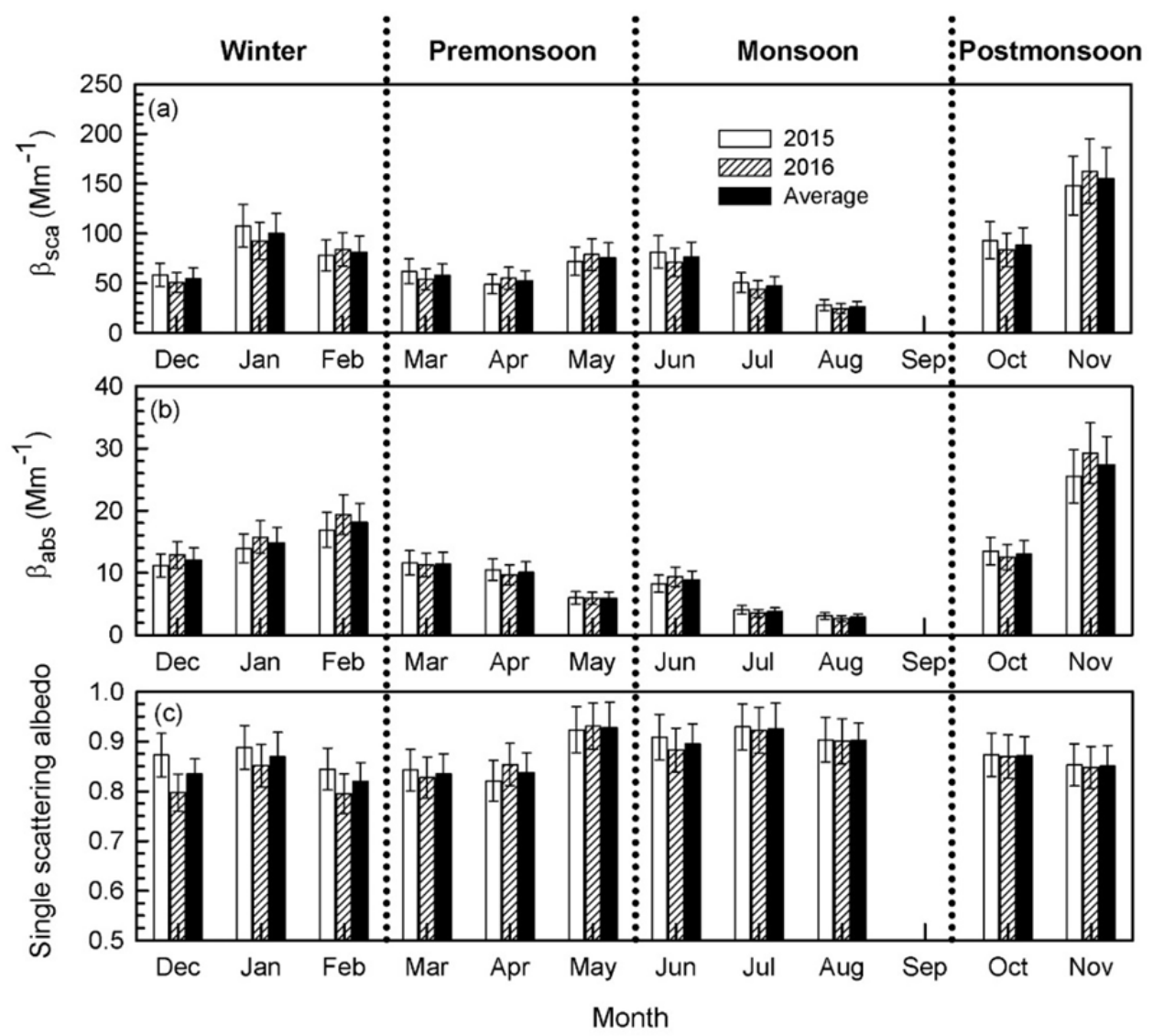

Fig. 7. Monthly variation in (a) aerosol scattering coefficient $\left(\beta_{\mathrm{sca}}, \mathrm{Mm}^{-1}\right)$, (b) aerosol absorption coefficient $\left(\beta_{\mathrm{abs}}, \mathrm{Mm}^{-1}\right)$, and (c) single scattering albedo (SSA) over Gurushikhar during 2015-2016 at $550 \mathrm{~nm}$. Vertical bars represent $\pm 1 \sigma$ variation about the mean. 
SSA (0.93) is observed during May as $95 \%$ of the long-range transported air masses are from Thar Desert and Arabian Sea (Fig. 3) which bring in more scattering type aerosols relative to the anthropogenic emissions from the valley/foothills, whereas the minimum SSA (0.82) is found during December as $85 \%$ of the long-range transported air is from the northern regions of India (Fig. 3) which brings in more absorbing type aerosols (black carbon) as compared to the contributions from the nearby valley regions. SSA decreases from July to December indicating a transition from the dominant scattering type aerosols to absorbing type aerosols.

In order to examine the spatial distribution of potential biomass burning sources which produces black carbon aerosols, which can influence aerosol absorption and SSA at the observational site, MODIS cloud corrected fire count version 5 monthly data available at $1^{\circ} \times 1^{\circ}$ resolution have been examined (Fig. 3). Fire counts exhibit large spatial variations over India (Fig. 3). The area infested by forest fires and biomass burning is high during winter and premonsoon as compared to monsoon and postmonsoon. During postmonsoon, Punjab and Haryana show high fire counts due to relative dominance of biomass burning (residue crop burning). In addition, premonsoon shows higher fire counts in the Indo-Gangetic Plain due to residue crop burning during this period over Punjab and Haryana (Fig. 3). The wind patterns play an important role in transporting the biomass aerosols from the biomass burning regions to the observational site through advection process (Fig. 3).

Low SSA during March and April reveals the dominance of absorbing type aerosols which get transported from the residue crop burning areas in Punjab and Haryana. SSA in March is marginally lower than April because 54\% of air trajectories originate from the residue crop burned source regions during March when compared to April. The MODIS fire count map shows highest fire density during May in the Punjab and Haryana region of northern India (Fig. 3) however, its effect is not observed over Gurushikhar as only $3 \%$ of the air parcels reaching the observational site are from this hot spot region, and $95 \%$ of the air trajectories are from the arid regions and Arabian Sea (Fig. 3). Highest SSA (0.90) is observed during monsoon followed by premonsoon (0.87) and postmonsoon $(0.86)$ (Table 3). Minimum SSA (0.84) is observed during winter due to the dominance of the absorbing type aerosols arriving at the observational site from the northern region of India. SSA is in the range of 0.83 to 0.91 with an annual mean value of 0.87 at $550 \mathrm{~nm}$ over Gurushikhar.

The seasonal mean $\beta_{\text {sca }}$ values observed over Gurushikhar are significantly lower than a nearby urban source location (Ahmedabad, situated at a distance of $200 \mathrm{~km}$ ) by a factor of 3 during winter and by a factor of 2 during premonsoon, monsoon and postmonsoon seasons. Unlike Gurushikhar, the highest $\beta_{\text {sca }}$ over Ahmedabad was observed during winter $\left(240 \mathrm{Mm}^{-1}\right)$ followed by postmonsoon, premonsoon and monsoon seasons (Kedia, 2010). A similar pattern in $\beta_{\text {sca }}$ and $\beta_{\text {abs }}$ was observed over another urban location (Delhi) in the Indo-Gangetic Plain with very high magnitude during winter ( 7 and 12 times higher than Gurushikhar $\beta_{\text {sca }}$ and $\beta_{\mathrm{abs}}$ values respectively) (Soni et al., 2010). The SSA during December is lower than the SSA reported over a cleaner site, Manora Peak, a high altitude site in the central Himalayas (0.90) (Pant et al., 2006). Annual mean SSA over Gurushikhar is significantly higher than those reported over Ahmedabad (0.78) (Ganguly et al., 2006), Delhi (0.70) (Soni et al., 2010), and Visakhapatnam (0.76) (Niranjan et al., 2011).

$\beta_{\text {sca }}$ and $\beta_{\text {abs }}$ exhibit less significant inter-annual variability (Figs. 7(a) and 7(b)). The observed monthly percentage change in $\beta_{\text {sca }}$ and $\beta_{\text {abs }}$ between 2015 and 2016 is $<15 \%$ (Figs. 7(a) and 7(b)) which is within the uncertainty of the measurements. A two-tailed p-value $(<0.05)$ between the SSA data for each month during 2015 and 2016 revealed that the inter-annual differences in SSA are lower than $10 \%$ which is less than the uncertainty in SSA estimate (15\%). The high altitude remote observational site (Gurushikhar) has minimal anthropogenic sources and the study reveals that aerosol characteristics over this pristine site is influenced mainly by the transport processes (convection and advection). The inter-annual variability in aerosol characteristics estimated for the two years (2015-2016) is found to be less significant and hence, Gurushikhar can be considered as a background representative for aerosols of the nearby source regions in western India.

\section{Comparison of Aerosol Properties with Other High Altitude Locations}

Aerosol scattering $\left(\beta_{\text {sca }}\right)$ and absorption $\left(\beta_{\text {abs }}\right)$ coefficients, and single scattering albedo (SSA) show significant variation at other high altitude locations across the globe with differences in their magnitude (Table 4). $\beta_{\text {sca }}$ and $\beta_{\text {abs }}$ values over Gurushikhar are found to be higher than other high altitude sites-Izana, Spain (Andrews et al., 2011); Mauna Loa, USA (Andrews et al., 2011); Monte Cimome, Italy (Andrews et al., 2011); Mount Lulin, Taiwan (Andrews et al., 2011); Mount Waliguan, China (Andrews et al., 2011); Mukteshwar, India (Hyvärinen et al., 2009); Nepal Climate Observatory-Pyramid (NCO-P; Andrews et al., 2011); and Whistler, Canada (Andrews et al., 2011) (Table 4) - and lower than Nainital, India (Dumka et al., 2015) (Table 4). Most of these high altitude sites exhibit

Table 3. Seasonal mean variations of aerosol scattering $\left(\beta_{\mathrm{sca}}\right)$, absorption $\left(\beta_{\mathrm{abs}}\right)$ coefficients, and single scattering albedo (SSA) over Gurushikhar during 2015-2016.

\begin{tabular}{llll}
\hline Season & $\beta_{\text {sca }}\left(\mathrm{Mm}^{-1}\right)$ & $\beta_{\mathrm{abs}}\left(\mathrm{Mm}^{-1}\right)$ & $\mathrm{SSA}$ \\
\hline Winter & $78.5 \pm 23.3$ & $15.0 \pm 3.4$ & $0.83 \pm 0.03$ \\
Premonsoon & $61.8 \pm 12.9$ & $9.1 \pm 2.4$ & $0.87 \pm 0.04$ \\
Monsoon & $49.9 \pm 25.2$ & $5.1 \pm 2.9$ & $0.90 \pm 0.03$ \\
Postmonsoon & $121.8 \pm 35.9$ & $20.2 \pm 7.5$ & $0.86 \pm 0.01$ \\
\hline
\end{tabular}


Table 4. Mean aerosol scattering $\left(\beta_{\text {sca }}\right)$, absorption $\left(\beta_{\text {abs }}\right)$ coefficients, and single scattering albedo (SSA) measured over Gurushikhar in comparison with other high altitude sites over the globe.

\begin{tabular}{|c|c|c|c|c|c|c|}
\hline Location & $\begin{array}{l}\text { Altitude } \\
\text { AMSL (m) }\end{array}$ & $\begin{array}{l}\text { Period } \\
\text { (years) }\end{array}$ & $\begin{array}{l}\beta_{\text {sca }} \\
\left(\mathrm{Mm}^{-1}\right)\end{array}$ & $\begin{array}{l}\beta_{\mathrm{abs}} \\
\left(\mathrm{Mm}^{-1}\right)\end{array}$ & SSA & Reference \\
\hline Gurushikhar, India & 1680 & $2015-2016$ & $78.0 \pm 31.5$ & $12.4 \pm 6.6$ & $0.87 \pm 0.03$ & Present study \\
\hline Izana, Spain & 2400 & 2008-2009 & 9.3 & 0.7 & 0.93 & Andrews et al. (2011) \\
\hline Mauna Loa, USA & 3400 & 2000-2009 & 1.9 & 0.1 & 0.97 & Andrews et al. (2011) \\
\hline Monte Cimome, Italy & 2200 & 2007-2009 & 17.2 & 2.5 & 0.88 & Andrews et al. (2011) \\
\hline Mount Lulin, Taiwan & 2900 & 2008-2009 & 25.8 & 2.8 & 0.90 & Andrews et al. (2011) \\
\hline Mount Waliguan, China & 3800 & $2005-2008$ & 42.5 & 2.3 & 0.95 & Andrews et al. (2011) \\
\hline Mukteshwar, India & 2180 & 2006-2009 & 53 & 11 & 0.81 & Hyvärinen et al. (2009) \\
\hline Nainital, India & 1958 & 2011-2012 & 177 & 14 & 0.93 & Dumka et al. (2015) \\
\hline NCO-P, Nepal & 5079 & $2006-2008$ & 17.4 & 1.6 & 0.91 & Andrews et al. (2011) \\
\hline Whistler, Canada & 2200 & 2008-2009 & 4.0 & 0.5 & 0.88 & Andrews et al. (2011) \\
\hline
\end{tabular}

higher SSA $(>0.80)$ which reveal the dominance of scattering type aerosols (Table 4). The observed variation of $\beta_{\text {sca }}, \beta_{\text {abs }}$, and SSA values in the high altitude remote site could be due to the prevailing local sources, meteorology and the long-range transport.

\section{CONCLUSIONS}

For the first time, aerosol optical properties (the scattering $\left(\beta_{\text {sca }}\right)$ and absorption $\left(\beta_{\text {abs }}\right)$ coefficients, observed from January 2015 to December 2016) at Gurushikhar $\left(24.65^{\circ} \mathrm{N}, 72.78^{\circ} \mathrm{E}, 1680 \mathrm{~m}\right.$ AMSL), Mt. Abu, a remote high altitude location in western India, have been analyzed. $\beta_{\text {sca }}$ and $\beta_{\mathrm{abs}}$ were measured using an integrating nephelometer and a dual spot aethalometer, respectively. The major findings of the study are:

1. $\beta_{\mathrm{sca}}$ and $\beta_{\mathrm{abs}}$ exhibited a peculiar diurnal variability with higher afternoon than forenoon and night values because of the fully evolved atmospheric boundary layer, which, accompanied by strong thermal convection, promotes an upward transport of aerosols to the mountain site from the surrounding foothills during the afternoon.

2. $\beta_{\mathrm{sca}}$ and $\beta_{\mathrm{abs}}$ displayed a strong seasonal variability and were highest during the postmonsoon season (121.8 and $\left.20.2 \mathrm{Mm}^{-1}\right)$, followed by winter $\left(78.5\right.$ and $\left.15.0 \mathrm{Mm}^{-1}\right)$, as the measurement site is influenced by convection from the foothills and advection through long-range transport. In addition, during the postmonsoon and winter seasons, biomass burning and tourist activity in the region significantly increase. The minimum $\beta_{\text {sca }}$ (49.9 $\mathrm{Mm}^{-1}$ ) and $\beta_{\mathrm{abs}}\left(5.1 \mathrm{Mm}^{-1}\right)$ occurred during the monsoon season due to wet removal by precipitation.

3. The monthly variability of $\beta_{\text {sca }}$ differed from that of $\beta_{\text {abs, }}$, but the mean seasonal $\beta_{\text {sca }}$ and $\beta_{\text {abs }}$ values were well correlated.

4. The single scattering albedo (SSA) exhibited significant seasonal variation, with the maximum value $(0.91)$ occurring during the monsoon season, followed by the premonsoon $(0.90)$, postmonsoon $(0.86)$ and winter (0.83) seasons.

5. $\beta_{\text {sca }}, \beta_{\text {abs }}$ and SSA did not exhibit any significant interannual variability.

6. Minimal anthropogenic sources exist at Gurushikhar, and the aerosol properties are governed mainly by atmospheric transport processes (convection and advection).

7. The aerosol properties at Gurushikhar display low inter-annual variability; hence, this high altitude remote observational site can be categorized as a representative background site for aerosols from nearby source regions in western India.

Our measurements correspond to regional background values for western India and can be used as representative inputs in various regional and global climate models to estimate climate forcing.

\section{ACKNOWLEDGMENTS}

We thank the ISRO-GBP, ISRO Headquarters, Bangaluru, for partial funding support under the ARFI project. Rainfall data is downloaded from TRMM (TMPA) Precipitation L3 1 day $0.25^{\circ} \times 0.25^{\circ} \mathrm{V} 7$, GES-DISC, NASA. The authors gratefully acknowledge the NOAA Air Resources Laboratory (ARL) for the HYSPLIT transport and dispersion model.

\section{REFERENCES}

Anderson, T.L. and Ogren, J.A. (1998). Determining aerosol radiative properties using the TSI 3563 integrating nephelometer. Aerosol Sci. Technol. 29: 57-69.

Andrews, E., Ogren, J.A., Bonasoni, P., Marinoni, A., Cuevas, E., Rodríguez, S., Sun, J.Y., Jaffe, D.A., Fischer, E.V., Baltensperger, U., Weingartner, E., Coen, M.C., Sharma, S., Macdonald, A.M., Leaitch, W.R., Lin, N.H., Laj, P., Arsov, T., Kalapov, I., Jefferson, A. and Sheridan, P. (2011). Climatology of aerosol radiative properties in the free troposphere. Atmos. Res. 102: 365393.

Arnott, W.P., Hamasha, K., Moosmüller, H., Sheridan, P.J. and Ogren, J.A. (2005). Towards aerosol light-absorption measurements with a 7-wavelength aethalometer: Evaluation with a photoacoustic instrument and 3wavelength nephelometer. Aerosol Sci. Technol. 39: 17-29. Drinovec, L., Močnik, G., Zotter, P., Prévôt, A.S.H., Ruckstuhl, C., Coz, E., Rupakheti, M., Sciare, J., Müller, 
T., Wiedensohler, A. and Hansen, A.D.A. (2015). The "dual-spot" Aethalometer: An improved measurement of aerosol black carbon with real-time loading compensation. Atmos. Meas. Tech. 8: 1965-1979.

Dumka, U.C., Kaskaoutis, D.G., Srivastava, M.K., Devara, P.C.S. (2015). Scattering and absorption properties of near-surface aerosol over Gangetic-Himalayan region: the role of boundary-layer dynamics and long-range transport. Atmos. Chem. Phys. 15: 1555-1572.

Ganguly, D., Jayaraman, A. and Gadhavi, H. (2006). Physical and optical properties of aerosols over an urban location in western India: Seasonal variabilities. $J$. Geophys. Res. 111: D24206.

Gundel, L., Dod, R., Rosen, H. and Novakov, T. (1984). The relationship between optical attenuation and black carbon concentration for ambient and source particles. Sci. Total Environ. 36: 197-202.

Hyvärinen, A.P., Lihavainen, H., Komppula, M., Sharma, V., Kerminen, V.M., Panwar, T. and Viisanen, Y. (2009). Continuous measurements of optical properties of atmospheric aerosols in Mukteshwar, northern India. J. Geophys. Res. 114: D08207.

Intergovernmental Panel on Climate Change (2007). Summary for policymakers, in Climate Change 2007: The Physical Science Basis. Contribution of Working Group I to the Fourth Assessment Report of the Intergovernmental Panel on Climate Change, Solomon, S. et al. (Eds.), Cambridge Univ. Press, New York, pp. 129-234.

Jayaraman, A., Gadhavi, H., Ganguly, D., Misra, A., Ramachandran, S. and Rajesh, T.A. (2006). Spatial variations in aerosol characteristics and regional radiative forcing over India: Measurements and modeling of 2004 road campaign experiment. Atmos. Environ. 40: 6504-6515.

Kedia, S. (2010). Regional and seasonal differences in aerosol radiative forcing over India and adjoining oceanic regions. Ph. D. Thesis, MLSU Udaipur.

Kedia, S. and Ramachandran, S. (2011). Seasonal variations in aerosol characteristics over an urban location and a remote site in western India. Atmos. Environ. 45: 21202128.

Kedia, S., Ramachandran, S., Kumar, A. and Sarin, M.M. (2010). Spatiotemporal gradients in aerosol radiative forcing and heating rate over Bay of Bengal and Arabian Sea derived on the basis of optical, physical, and chemical properties. J. Geophys. Res. 115: D07205.

Kovalev, V.A. and Eichinger, W.E. (2004). Elastic lidar: Theory, practice, and analysis methods. John Wiley \& Sons.

Li, J., Li, P., Yuan, L., Yin, Y., Wang, Z., Li, J., Li, Y., Ren, G. and Cai, Z. (2017). Physical and optical properties of atmospheric aerosols in summer at a suburban site in North China. Aerosol Air Qual. Res. 17: 1474-1488.

Niranjan, K., Spandana, B., Devi, T.A., Sreekanth, V. and
Madhavan, B.L. (2011). Measurements of aerosol intensive properties over Visakhapatnam, India for 2007. In Annales geophysicae, Vol. 29, No. 6, p. 973.

Pant, P., Hegde, P., Dumka, U.C., Sagar, R., Satheesh, S.K., Moorthy, K.K., Saha, A. and Srivastava, M.K. (2006). Aerosol characteristics at a high-altitude location in central Himalayas: Optical properties and radiative forcing. J. Geophys. Res. 111: D17206.

Rajesh, T.A. and Ramachandran, S. (2018). Black carbon aerosol mass concentration, absorption and single scattering albedo from single and dual spot aethalometers: Radiative implications. J. Aerosol Sci. 119: 77-90.

Ramachandran, S., and Kedia, S. (2010). Black carbon aerosols over an urban region: Radiative forcing and climate impact. J. Geophys. Res. 115: D10202.

Reddy, B.S.K., Kumar, K.R., Balakrishnaiah, G., Gopal, K.R., Reddy, R.R., Reddy, L.S.S., Ahammed, Y.N., Narasimhulu, K., Moorthy, K.K. and Babu, S.S. (2012). Potential source regions contributing to seasonal variations of black carbon aerosols over Anantapur in Southeast India. Aerosol Air Qual. Res. 12: 344-358.

Russell, P.B., Redemann, J., Schmid, B., Bergstrom, R.W., Livingston, J.M., McIntosh, D.M., Ramirez, S.A., Hartley, S., Hobbs, P.V., Quinn, P.K. and Carrico, C.M. (2002). Comparison of aerosol single scattering albedos derived by diverse techniques in two North Atlantic experiments. J. Atmos. Sci. 59: 609-619.

Soni, K., Singh, S., Bano, T., Tanwar, R.S., Nath, S. and Arya, B.C. (2010). Variations in single scattering albedo and Angstrom absorption exponent during different seasons at Delhi, India. Atmos. Environ. 44: 4355-4363.

Stull, R.B. (1998). An introduction to boundary layer meteorology. Kluwer Academic Publishers, The Netherland.

Tiwari, S., Bisht, D.S., Srivastava, A.K., Pipal, A.S., Taneja, A., Srivastava, M.K. and Attri, S.D. (2014). Variability in atmospheric particulates and meteorological effects on their mass concentrations over Delhi, India. Atmos. Res. 145: 45-56.

Virkkula, A., Mäkelä, T., Hillamo, R., Yli-Tuomi, T., Hirsikko, A., Hämeri, K. and Koponen, I.K. (2007). A simple procedure for correcting loading effects of aethalometer data. J. Air Waste Manage. Assoc. 57: 1214-1222.

Weingartner, E., Saathoff, H., Schnaiter, M., Streit, N., Bitnar, B. and Baltensperger, U. (2003). Absorption of light by soot particles: determination of the absorption coefficient by means of aethalometers. J. Aerosol Sci. 34: 1445-1463.
Received for review, June 11, 2018 Revised, February 27, 2019 Accepted, March 19, 2019 